\title{
LYSOGENICITY OF METHICILLIN-RESISTANT STRAINS OF STAPHYLOCOCCUS AUREUS
}

\author{
Mary A. Beard-Pegler ANd Alison M. VicKery* \\ Department of Infectious Diseases, The University of Sydney, Sydney, NSW 2006 and \\ * Department of Microbiology, Fairfax Institute of Pathology, Royal Prince Alfred \\ Hospital, Sydney, Australia
}

\begin{abstract}
Summary. The lysogenic status of 23 strains of methicillin-resistant Staphylococcus aureus, isolated at the Royal Prince Alfred Hospital, Sydney, since 1980, was studied. Twenty strains, belonging to the four predominant phage types isolated in this hospital, carried the same lysogenic phage which we have designated $\mathrm{C}$. Three other phages were isolated from five strains belonging to phage type 84/85/90. The presence of phage $\mathrm{C}$ had little effect on the phage-typing pattern of the strains. Similarly, lysogenisation with the other three phages did not result in a significant change in phage-typing patterns. However, when strain 1489 , isolated in 1969 , was lysogenised with these three phages, there was a change in phage-typing pattern. Lysogenisation of this strain with phage $47 \mathrm{~T}$ resulted in a marked loss of sensitivity to both group-I and group-III phages. The lysogenic status of these methicillin-resistant strains of $S$. aureus was compared with that of strains isolated between 1967 and 1970 . There was no evidence that the strains isolated recently were either related to, or derived from, the earlier ones.
\end{abstract}

\section{INTRODUCTION}

Methicillin-resistant strains of Staphylococcus aureus (MRSA) are being increasingly reported as causes of nosocomial infections in Australia (McDonald et al., 1981; King et al., 1982; Pavillard et al., 1982) and in other countries (Schaefler et al., 1981; Linneman et al., 1982; Archer and Mayhall, 1983; Cafferkey et al., 1983). These strains are difficult to type with the Basic International Set of phages (Archer and Mayhall, 1983). Schaefler et al. (1981) reported that a large percentage of methicillin-resistant strains isolated in New York City was not typable with the Basic International Set when used at the routine test dilution (RTD) or at 100RTD, but was typable only by experimental phages. Cafferkey et al. (1983) also reported the emergence, in 1977, of strains of MRSA untypable with the routine set of phages.

The differentiation of MRSA strains, isolated at Royal Prince Alfred Hospital (RPAH), Sydney, by phage typing with the Basic International Set of phages at 100RTD and an additional set of phages has been reported (Vickery et al., 1983). Since 
1980 , strains belonging to four phage patterns have predominated and these differed in phage type from strains isolated between 1967 and 1970 (Rountree and Beard, 1968; Rountree and Vickery, 1973). The presence of a prophage in a strain of S. aureus may affect the phage-typing pattern of that strain (Blair and Carr, 1961; Rountree and Asheshov 1961; Duval-Iflah, 1972). Four typical but different earlier MRSA strains were each shown to contain two lysogenic phages (Vickery, unpublished observation) and the question arose as to whether or not the more recent strains were lysogenically similar to, or could have been derived from, the earlier strains.

\section{MATERIALS AND METHODS}

Strains of S. aureus. All strains of MRSA were isolated at the Royal Prince Alfred Hospital, Sydney. They were slide coagulase positive and were stored on nutrient-agar slopes at room temperature. Strains 1489 and 8947 have been described (Vickery et al., 1983). Five strains of each of four predominant phage types isolated since 1980 were tested for the presence of lysogenic phages. A sixth strain 10335, isolated in December 1983, was also studied. Propagating and indicator strains of the Basic International Set of phages were used to determine the host ranges of all phages.

Media and antibiotic sensitivity testing. These methods and materials have been previously described (Vickery et al., 1983).

Phages. Phage typing was performed by the method of Blair and Williams (1961) with the Basic International Set of 23 phages and three experimental phages, 187, 90 and 88, issued by the International Reference Laboratory, Colindale (Asheshov and Skalova, 1975); the typing patterns are reported at 100RTD. Five additional phages isolated from MRSA (Vickery et al., 1983) were also used to type the strains, and the typing patterns are reported at RTD. Lysogenic phages were obtained by induction of MRSA with UV light by the method of Gorrill and Gray (1956), and propagated on strain 1489 to obviate any possible host modification. All new phages were characterised by their host range and serological type (Rippon, 1956). Lysogenic phages were numbered according to the strain of staphylococcus from which they were derived, e.g., phage $87 \mathrm{M}$ was a phage of medium plaque size from strain 1987 and phage $87 \mathrm{~L}$ was a large-plaque phage from the same strain; phage 67R was a phage with a rough edged plaque from strain 8967 and phage 47T was a tiny-plaque phage from strain 8947.

Lysogenisation. Staphylococcal strains were lysogenised by spotting undiluted phage on to a lawn of cocci. After incubation overnight at $30^{\circ} \mathrm{C}$, a small quantity of the secondary bacterial growth in the area of lysis was streaked on to blood agar plates. After incubation overnight at $37^{\circ} \mathrm{C}$, single colonies were picked into broth and tested for the presence of the lysogenising phage, for resistance to it, and for alteration in phage-typing pattern. The lysogenised strains were numbered in the usual way, e.g., strain 1489 (87M) indicated strain 1489 lysogenised with phage $87 \mathrm{M}$.

\section{RESULTS}

\section{Lysogenicity of MRSA strains}

Phages were isolated from 21 strains of MRSA (table I). Characterisation of these phages, by determining their host range and serology, showed that an identical large-plaque phage designated $\mathrm{C}$ (common), was isolated from all strains. From the strains belonging to phage types $83 \mathrm{~A} / 85 / 95 / 90 / 88$ and $77 / 83 \mathrm{~A} / 84 / 85 / 95 / 90 / 88$ and from untypable strains, this phage only was isolated. However, from three of the five strains of phage type $84 / 85 / 90$, additional phages were isolated. Strain 8967 yielded phage $C$ and phage 67R; phage $C$ and phage $87 \mathrm{M}$ were isolated from strain 1987 and 
TABLE I

Lysogenicity of methicillin-resistant S. aureus

\begin{tabular}{|c|c|c|c|}
\hline \multicolumn{2}{|c|}{ Typing patterns with } & \multirow[b]{2}{*}{ Strain no. } & \multirow[b]{2}{*}{$\begin{array}{c}\text { Lysogenic } \\
\text { phages } \\
\text { isolated }\end{array}$} \\
\hline $\begin{array}{l}\text { Basic International } \\
\text { Set of phages at } \\
\text { 100RTD }\end{array}$ & $\begin{array}{l}\text { Additional phages } \\
\text { at RTD }\end{array}$ & & \\
\hline $83 \mathrm{~A} / 85 / 95 / 90 / 88$ & $47 \mathrm{~T} / 90 \mathrm{~A}$ & $\begin{array}{r}346 \\
10324 \\
10318 \\
10519 \\
10347\end{array}$ & $\begin{array}{l}C \\
C \\
C \\
C \\
C\end{array}$ \\
\hline $77 / 83 \mathrm{~A} / 84 / 85 / 95 / 90 / 88$ & $47 \mathrm{~T} / 56 \mathrm{~A} / 56 \mathrm{C} / 90 \mathrm{~A}$ & $\begin{array}{r}6333 \\
9337 \\
9378 \\
2010 \\
10531\end{array}$ & $\begin{array}{l}C \\
C \\
C \\
C \\
C\end{array}$ \\
\hline Not Typable & Not Typable & $\begin{array}{r}675 \\
8554 \\
8134 \\
1648 \\
4112\end{array}$ & $\begin{array}{l}\mathrm{C} \\
\mathrm{C} \\
\mathrm{C} \\
\mathrm{C} \\
\mathrm{C}\end{array}$ \\
\hline $84 / 85 / 90$ & $56 \mathrm{~B} / 56 \mathrm{C} / 90 \mathrm{~A}$ & $\begin{array}{r}8947 \\
8967 \\
9164\end{array}$ & $\begin{array}{l}\mathrm{C}, 47 \mathrm{~T} \\
\mathrm{C}, \underset{\mathrm{C}}{\mathrm{C}}\end{array}$ \\
\hline & $\begin{array}{l}56 \mathrm{~A} / 56 \mathrm{C} \\
90 \mathrm{~A}\end{array}$ & $\begin{array}{r}10359 \\
1987\end{array}$ & $\begin{array}{c}\mathrm{C} \\
\mathrm{C}, 87 \mathrm{M}\end{array}$ \\
\hline $77 / 85$ & $56 \mathrm{~A} / 56 \mathrm{C}$ & 10335 & $\mathrm{C}, 47 \mathrm{~T}$ \\
\hline
\end{tabular}

strain 8947 yielded phage $47 \mathrm{~T}$ as well as phage $C$. No additional phages were detected from strains 9164 and 10359 .

Strain 10335 , of phage type $77 / 85: 56 \mathrm{~A} / 56 \mathrm{C}$, was the first MRSA of this phage pattern to be isolated at RPAH, although identical strains had been isolated in one other Sydney hospital. Two phages, $\mathrm{C}$ and $47 \mathrm{~T}$, were isolated from this strain.

Two other MRSA, of phage type 83A/85/95/90/88:47T/90A but sensitive to phage $\mathrm{C}$, were induced by UV irradiation. No lysogenic phages were detected from either strain.

\section{Characterisation of lysogenic phages}

Phage $\mathrm{C}$ belonged to serological group $\mathrm{F}$ (table II) and had a restricted host range, lysing group-III propagating strains 6,47,85,90 and 88. Phage 67R lysed group-II strain $3 \mathrm{C}$ and several group-III strains and belonged to serological group A. Phage $87 \mathrm{M}$ lysed group-I strain 52 and group-III strains $6,54,75,83 \mathrm{~A}, 84,85,90,88$ and belonged to serological group F. Phage 47T has already been used for routine typing in the additional set of phages reported by Vickery et al. (1983), and is included in table II for reference.

The influence of the presence of these phages on phage-typing patterns of MRSA strains was determined by lysogenisation studies. As expected in the following results, all lysogenised strains had lost sensitivity to the lysogenising phage. 
TABLE II

Characterisation of lysogenic phages from methicillin-resistant $S$. aureus

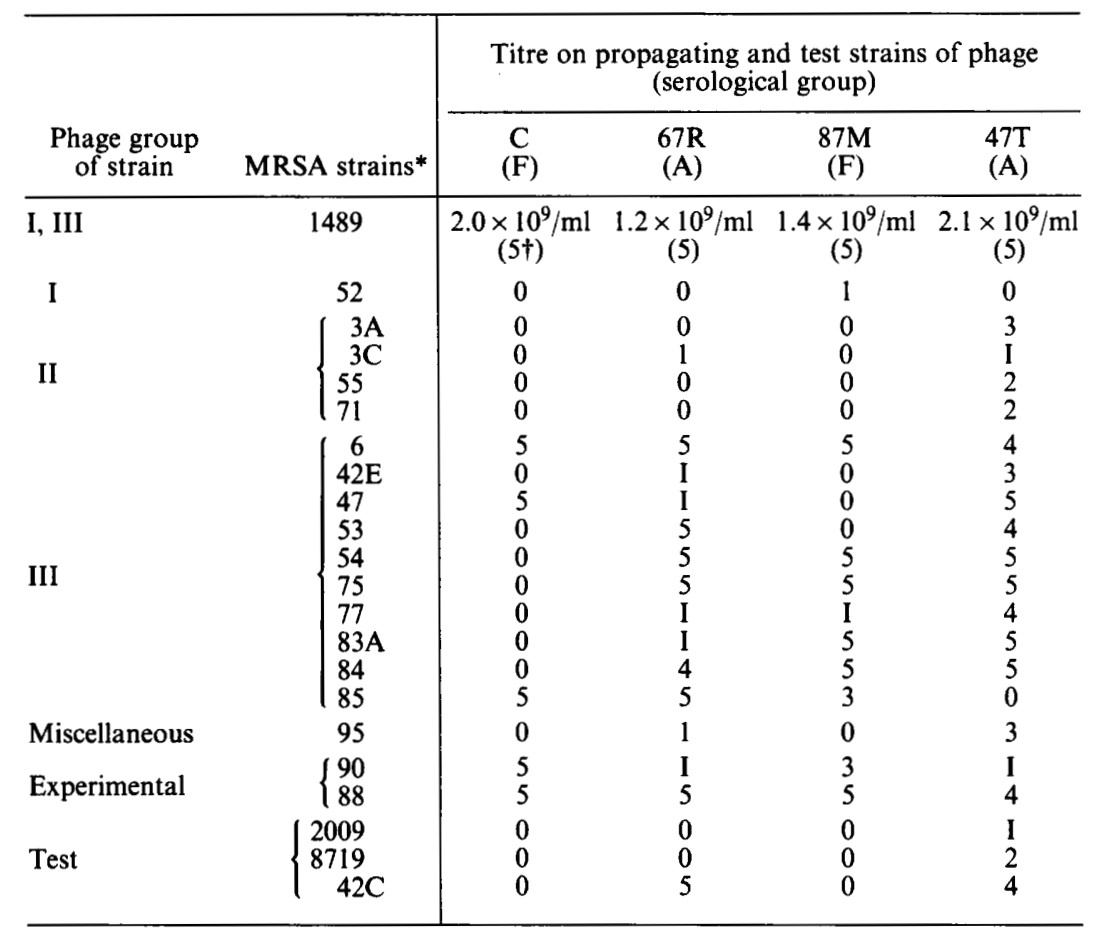

* Strains $29,52 \mathrm{~A} / 79,80,81,94,96,187,3 \mathrm{~B}$ were not lysed by these phages.

$\dagger 5=$ Titre on propagating strain $1489 ; 4=10^{-1}-10^{-2}, 3=10^{-3}-10^{-4}, 2=10^{-5}-10^{-6}$ of titre on 1489 ; $I=$ very weak lysis; $0=$ no lysis; $I=$ inhibition reaction.

\section{Lysogenisation of strain 1489}

Strain 1489 is a MRSA strain isolated at RPAH in 1969. It is apparently non-lysogenic, because all attempts to isolate lysogenic phages from it have been unsuccessful and it was sensitive to a wide range of phages. The absence of prophage in this strain indicated that there should be no interaction between lysogenic phages and any phage isolate propagated on it. Because of the wide sensitivity of this strain to group-I and group-III phages of the Basic International Set of phages, it was used as a test strain to observe the effect of lysogenisation, with the new phage isolates, on its phage-typing pattern.

Table III shows that lysogenisation with phage $\mathrm{C}$ had little effect on the phage-typing pattern of strain 1489 and resulted only in reduced sensitivity to phage 85. When phage $47 \mathrm{~T}$ was introduced, a marked loss of sensitivity to group-I and group-III phages occurred. When the double lysogen 1489(C) (47T) was tested, an additive loss of phage sensitivity resulted. Strains $1489(67 R)$ and $1489(87 \mathrm{M})$ showed loss of sensitivity to different group-III phages. The double lysogens $1489(\mathrm{C})(67 \mathrm{R})$ and 1489(C) (87M) also showed an additive loss of phage sensitivity.

None of the lysogenised strains 1489(C) (47T), 1489(C) (67R) and 1489(C) (87M) 


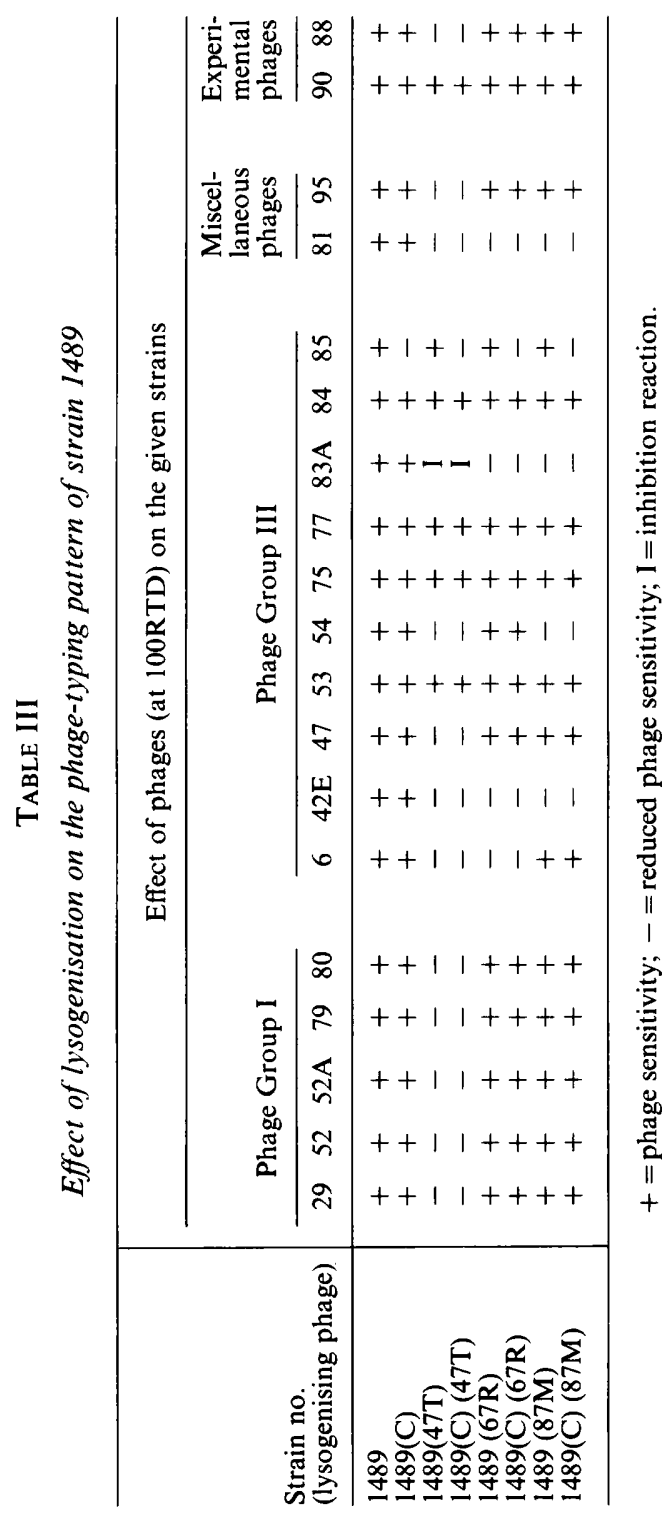


showed phage-typing patterns identical to those of the original host strains 8947,8967 and 1987 respectively.

There was no change in the sensitivity of strain 1489 to phages $47 \mathrm{~T}, 67 \mathrm{R}$ or $87 \mathrm{M}$ after lysogenisation with phage $C$; nor was there any change in the sensitivity of this strain to phages $C, 67 \mathrm{R}$ or $87 \mathrm{M}$ after lysogenisation with phage $47 \mathrm{~T}$. However, there was cross immunity between phages $67 \mathrm{R}$ and $87 \mathrm{M}$ when they were introduced into strain 1489.

\section{Lysogenisation with phage $C$}

Only $1.6 \%$ of 748 MRSA strains isolated recently at RPAH were sensitive to phage C. All these sensitive strains belonged to phage type $83 \mathrm{~A} / 85 / 95 / 90 / 88$. Two of these strains were lysogenised with phage $C$ and the only change in sensitivity observed was a reduction in sensitivity to phage 85 . Three other MRSA strains isolated earlier and of phage type $6 / 7 / 54 / 84 / 85 / 88$ at RTD, were also lysogenised with phage $C$ and all showed similar reduced sensitivity only to phage 85 . It appears, therefore, that phage $C$ has little effect on phage-typing patterns.

\section{Lysogenisation with phage $47 T$}

When strains of phage-type 83A/85/95/90/88:47T/90A were lysogenised with phage $47 \mathrm{~T}$, they showed loss of sensitivity to phage 88 only (table IV). However, when strains of phage type 77/83A/84/85/95/90/88:47T/56A/56C/90A were lysogenised, they showed loss of sensitivity to phage $83 \mathrm{~A}, 84,95,90,88$ and $90 \mathrm{~A}$. The phage patterns of the lysogenised strains thus became $77 / 85: 56 \mathrm{~A} / 56 \mathrm{C}$, which was identical to that of strain 10335 . Only two strains of phage-pattern $84 / 85 / 90$ were sensitive to phage $47 \mathrm{~T}$. They were sensitive to this phage at 100RTD only. They were strain 8967 of phage-type 84/85/90:56B/56C/90A and strain 1987 of phage-type 84/85/90:90A. After lysogenisation, there was no change in their phage-sensitivity patterns.

TABLE IV

Effect of lysogenisation on phage-typing patterns of strains of methicillin-resistant S. aureus

\begin{tabular}{|c|c|c|c|c|}
\hline \multicolumn{2}{|c|}{ Typing patterns with } & \multirow[b]{2}{*}{$\begin{array}{c}\text { Lysogenising } \\
\text { phage }\end{array}$} & \multicolumn{2}{|c|}{$\begin{array}{c}\text { Changes* in phage sensitivity } \\
\text { after lysogenisation }\end{array}$} \\
\hline $\begin{array}{l}\text { Basic International Set } \\
\text { of phages at } 100 \text { RTD }\end{array}$ & $\begin{array}{c}\text { Additional phages } \\
\text { at RTD }\end{array}$ & & Gains & 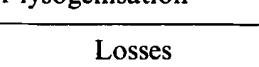 \\
\hline $\begin{array}{l}83 \mathrm{~A} / 85 / 95 / 90 / 88 \\
77 / 83 \mathrm{~A} / 84 / 85 / 95 / 90 / 88 \\
84 / 85 / 90 \\
84 / 85 / 90 \\
84 / 85 / 90 \\
83 \mathrm{~A} / 85 / 95 / 90 / 88 \\
84 / 85 / 90 \\
\quad \text { Not Typable }\end{array}$ & $\begin{array}{c}47 \mathrm{~T} / 90 \mathrm{~A} \\
47 \mathrm{~T} / 56 \mathrm{~A} / 56 \mathrm{C} / 90 \mathrm{~A} \\
56 \mathrm{~B} / 56 \mathrm{C} / 90 \mathrm{~A} \\
90 \mathrm{~A} \\
56 \mathrm{~B} / 56 \mathrm{C} / 90 \mathrm{~A} \\
47 \mathrm{~T} / 90 \mathrm{~A} \\
56 \mathrm{~B} / 56 \mathrm{C} / 90 \mathrm{~A} \\
\text { Not Typable }\end{array}$ & $\begin{array}{l}47 \mathrm{~T} \\
47 \mathrm{~T} \\
47 \mathrm{~T} \\
47 \mathrm{~T} \\
67 \mathrm{R} \\
87 \mathrm{M} \\
87 \mathrm{M} \\
87 \mathrm{M}\end{array}$ & $\begin{array}{c}- \\
- \\
- \\
\overline{-} \\
47,54,75 \\
- \\
- \\
-\end{array}$ & $\begin{array}{c}88 \\
83 \mathrm{~A}, 84,95,90,88,90 \mathrm{~A} \\
- \\
- \\
- \\
- \\
- \\
-\end{array}$ \\
\hline
\end{tabular}

$*-=$ No change. 


\section{Lysogenisation with phages $67 R$ and $87 M$}

Few strains of MRSA isolated at RPAH are sensitive to phage 67R. Strains of phage-types $83 \mathrm{~A} / 85 / 95 / 90 / 88$ and $77 / 83 \mathrm{~A} / 84 / 85 / 95 / 90 / 88$ and untypable strains that were studied were not sensitive, and only two strains, 8947 and 9164 , of phage-type $84 / 85 / 90: 56 \mathrm{~B} / 56 \mathrm{C} / 90 \mathrm{~A}$ were sensitive to it. These two strains were lysogenised with phage $67 \mathrm{R}$ and both showed slight gain in sensitivity to phages 47,54 and 75 at 100RTD only. There was no loss in sensitivity to any of the phages tested (table IV).

All strains, including the Not Typable group, showed some degree of sensitivity to phage $87 \mathrm{M}$. Strains of phage-type 77/83A/84/85/95/90/88 showed only slight sensitivity and could not be lysogenised. When strains of the other three phage types were lysogenised, there was no change in their phage-sensitivity patterns. The usefulness of this phage in strain differentiation of MRSA is being assessed.

There was no evidence, in any strain lysogenised with phages $47 \mathrm{~T}, 67 \mathrm{R}$ or $87 \mathrm{M}$, of prophage substitution of phage $\mathrm{C}$.

\section{Discussion}

These results indicate that the strains of methicillin-resistant $S$. aureus isolated recently at RPAH are related on the basis of their lysogenicity. Although they can be differentiated into consistent and reproducible phage-typing patterns, almost all carry the same lysogenic phage C. Strains of three phage types-83A/85/95/90/88, $77 / 83 \mathrm{~A} / 84 / 85 / 95 / 90 / 88$ and untypable - carry no other detectable lysogenic phages. Schaefler et al. (1981) reported a similar situation in MRSA strains of phage-type 88 isolated at three hospitals in New York City. The lysogenic phage carried by their strains differs from phage $\mathrm{C}$ in host range, although both phages have restricted host ranges.

None of the phages isolated in this study was identical to any phage from the Basic International Set nor to any other phage previously isolated from MRSA strains (Schaefler et al., 1981; Vickery et al., 1983; Vickery, unpublished data). Phage $\mathrm{C}$ has not been detected in methicillin-sensitive strains of $S$. aureus tested in this hospital.

Lysogenisation of strain 1489 with the phages isolated from the MRSA strains isolated recently resulted in a change of phage-typing pattern, but failed to convert the pattern to that of the original host strains. This is in contrast to the situation found in the strains isolated earlier, in which the phage-typing pattern of strain 1489, after lysogenisation with the lysogenic phages from those strains, converted to that of the original host strains (Vickery, unpublished data). Moreover, lysogenisation of three early MRSA strains with phage $\mathrm{C}$ had little effect on their typing patterns. This result was also observed in recently isolated MRSA strains sensitive to phage C.

Strains of phage-type 84/85/90 appear to be a more heterogenous group than the strains of other types. As well as phage $\mathrm{C}$ they carry other lysogenic phages. Lysogenisation with these phages had very little effect on the typing pattern of MRSA strains isolated recently except in one instance. Lysogenisation of strains of phage type $77 / 83 \mathrm{~A} / 84 / 85 / 95 / 90 / 88: 47 \mathrm{~T} / 56 \mathrm{~A} / 56 \mathrm{C} / 90 \mathrm{~A}$ by phage $47 \mathrm{~T}$ converted their phage type to $77 / 85: 56 \mathrm{~A} / 56 \mathrm{C}$, that of the naturally occurring MRSA strain 10335 , which carried lysogenic phages identical to those of the lysogenised strains. This suggests, therefore, that the typing pattern of strain 10335 is influenced by its lysogenic phages, and that 
this strain appears to have acquired phage 47T in vivo. Asheshov and Rippon (1959) suggested that, in type 80 strains of staphylococci, changes in phage-typing patterns may occur in nature.

The phage-typing differences between strains of patterns $83 \mathrm{~A} / 85 / 95 / 90 / 88$ and $77 / 83 \mathrm{~A} / 84 / 85 / 95 / 90 / 88$ cannot be ascribed to their lysogenicity, because strains of these patterns carry the identical phage $C$ and no other prophage has been detected in them. Moreover, the untypable strains also carry this prophage that produces immunity only to phage 85 .

It was noted that the untypable stains, from time to time, produced mutants which were sensitive to phages $47 \mathrm{~T}$ and $90 \mathrm{~A}$. The block in phage sensitivity in the untypable strains appears, therefore to be a phenotypic character, depending on an unknown factor in the strain. It is not due to restriction enzymes because it cannot be removed by heating (Asheshov and Jevons, 1963).

A close relationship between the MRSA strains isolated recently has been demonstrated by plasmid DNA analysis. Townsend et al. (1983) found that recently isolated MRSA strains appeared to be different from previously reported MRSA strains. Lyons et al. (1984) found that although MRSA strains possessed related plasmid profiles, there was some variation in the restriction digest patterns of plasmids in strains from individual hospitals.

These studies of lysogenicity have produced no evidence that MRSA strains isolated recently are related to or may have been derived from those strains prevalent in RPAH between 1967 and 1970 . Their origin is of great epidemiological interest and is being investigated further.

We thank Dr Phyllis Rountree for her invaluable advice, continuing interest and encouragement, Theresa Rice for her technical assistance and Suzanne Slocombe for her assistance with the preparation of this manuscript.

\section{REFERENCES}

Archer G L, Mayhall C G 1983 Comparison of epidemiological markers used in the investigation of an outbreak of methicillin-resistant Staphylococcus aureus infections. Journal of Clinical Microbiology 18:395-399.

Asheshov E H, Jevons M P 1963 The effect of heat on the ability of a host strain to support the growth of a staphylococcus phage. Journal of General Microbiology 31:97-107.

Asheshov E H, Rippon J E 1959 Changes in typing pattern of phage-type 80 staphylococci. Journal of General Microbiology 20:634-643.

Asheshov E H, Skalova R 1975 International committee on systematic bacteriology subcommittee on the phage-typing of staphylococci. International Journal of Systematic Bacteriology 35:233-234.

Blair J E, Carr M 1961 Lysogeny in staphylococci. Journal of Bacteriology 82:984-993.

Blair J E, Williams R E O 1961 Phage typing of staphylococci. Bulletin of the World Health Organisation 24:771-784.

Cafferkey M T, Hone R., Falkiner F R, Keane C T, Pomeroy H 1983 Gentamicin and methicillin resistant Staphylococcus aureus in Dublin hospitals: clinical and laboratory studies. Journal of Medical Microbiology 16:117-127.

Duval-Iflah Y 1972 Lysogenic conversion of the lipase in Staphylococcus pyogenes group III strains. Canadian Journal of Mirobiology 18:1491-1497.

Gorrill R H, Gray R A 1956 The induction of bacteriophage in staphylococci. Journal of General Microbiology 14:167-173.

King K, Brady L, Thomson L, Harkness J L 1982 Antibiotic-resistant staphylococci in a teaching hospital. Medical Journal of Australia 2:461-465. 
Linnemann C C, Mason M, Moore P, Korfhagen T R, Staneck J L 1982 Methicillin-resistant Staphylococcus aureus: experience in a general hospital over four years. American Journal of Epidemiology 115:941-950.

Lyon B R, Iuorio J L, May J W, Skurray R A 1984 Molecular epidemiology of multiresistant Staphylococcus aureus in Australian hospitals. Journal of Medical Microbiology 17:79-89.

McDonald M, Hurse A, Sim K N 1981 Methicillin-resistant Staphylococcus aureus bacteraemia. Medical Journal of Australia 1:191-194.

Pavillard R, Harvey K, Douglas D, Hewstone A, Andrew J, Collopy B, Asche V, Carson P, Davidson A, Gilbert G, Spicer J, Tosolini F 1982 Epidemic of hospital-acquired infection due to methicillin-resistant Staphylococcus aureus in major Victorian hospital. Medical Journal of Australia 1:451-454.

Rippon J E 1956 The classification of bacteriophages lysing staphylococci. Journal of Hygiene 54:213-226.

Rountree P M, Asheshov E H 1961 Further observations on changes in the phage-typing pattern of phage type 80/81 staphylococci. Journal of General Microbiology 26:111-122.

Rountree P M, Beard M A 1968 Hospital strains of Staphylococcus aureus, with particular reference to methicillin-resistant strains. Medical Journal of Australia 2:1163-1168.

Rountree P M, Vickery A M 1973 Further observations on methicillin-resistant staphylococci. Medical Journal of Australia 1:1030-1034.

Schaefler S, Jones D, Perry W, Ruvinskaya L, Baradet T, Mayr E, Wilson M E 1981 Emergence of gentamicin-resistant and methicillin-resistant Staphylococcus aureus strains in New York City hospitals. Journal of Clinical Microbiology 13:754-759.

Townsend D E, Grubb W B, Ashdown N 1983 Genetics of drug resistance in methicillin-resistant Staphylococcus aureus from Australian hospitals. Journal of Hospital Infection 4:331-337.

Vickery A M, Beard-Pegler M A, Rountree P M 1983 Strain differentiation in methicillin-resistant Staphylococcus aureus. Pathology 15:235-240. 